\title{
Fisheries-Independent Evidence of Longline Fisheries Impact on the Threatened Mediterranean Blue Shark Prionace Glauca in The Waters Around the Balearic Islands (Spain)
}

\author{
Ana-Maria Abril ${ }^{1,2}$, Clémentine Séguigne ${ }^{3,4}$, Gilles Siu ${ }^{3,4}$, Agusti Torres ${ }^{1}$ and Eric Clua ${ }^{1,3,4 *}$ \\ ${ }^{1}$ Shark-Med association, Spain
}

${ }^{2}$ Department de Biologia Cra de Valldemossa, Universitat de les Illes Balears, Spain

${ }^{3}$ PSL Université Paris: EPHE-UPVD-CNRS, French Polynesia

${ }^{4}$ Laboratoire d'Excellence CORAIL, France

Submission: August 03, 2020; Published: September 16, 2020

Corresponding author: Eric Clua, PSL Université Paris: EPHE-UPVD-CNRS, USR 3278 CRIOBE BP 1013, 98729 Papetoai, Moorea, French Polynesia Email:eric.clua@univ-perp.fr

\begin{abstract}
The Mediterranean Sea is one of the seas most affected by the collapse of shark populations due to overfishing. Considered 'vulnerable' by the IUCN on a global scale, the blue shark Prionace glauca is classified as 'Critically Endangered' in the Mediterranean Sea. A fisheries-independent study was conducted through the implementation of 14 filming sessions, lasting between 5 and 10 days, during winter and summer seasons between July 2017 and February 2020, in semi-pelagic waters around the islands of Mallorca and Menorca (Balearic Islands, Western Mediterranean). Using 24-hour BRUVs, we collected 1685 hours of video that allowed us to observe 10 blue sharks, six males and four females, estimated between 1.2 and $2.5 \mathrm{~m}$ in total length (TL). In addition to their low abundance (average of 0.02 shark $\pm 0,025$ observed per hour), $50 \%$ of animals presented residual hook, sometimes with a nylon leader several meters long, potentially jeopardizing its survival. In addition to other threats, the frequent presence of residual hooks may contribute to a cryptic mortality of this species in relation to pelagic fisheries, calling into question the future of this species in this region of the world.
\end{abstract}

Keywords: Shark conservation; Residual hooks; Olfactive attraction; Baited Remote Underwater Video (BRUV); Cryptic mortality

\section{Introduction}

Throughout the world's maritime areas, the Mediterranean has suffered some of the most significant shark stock collapses in recent decades, with several species experiencing declines of more than $90 \%$ and some as much as $99 \%$ [1]. The latest vulnerability status report for shark species implemented by the International Union for the Nature Conservation (IUCN) concludes that 56\% (23 of 41 species) face a high risk of extinction and that no status of a single species has improved since the 2007 assessment $[2,3]$. The reason for these declines is mainly due to overfishing and, for pelagic sharks, specifically by-catch retained on board in the pelagic swordfish and tuna longline fisheries [1]. Among the pelagic sharks concerned, the blue shark Prionace glauca has been the subject of several studies because of the vulnerability of the Mediterranean populations both in its western part as for the Balearic and Maltese waters and in its eastern part as for the Aegian sea [4-8]. The current trend suggests that populations of blue sharks continue to decline, particularly in the face of increased fishing effort on sharks in response to stricter legislation on swordfish and tuna catches [2].

This hypothesis of an increasing pressure on the blue shark was recently supported through a study which revealed the direct targeting of this species by Spanish fisheries in the NorthWestern Mediterranean [5]. Some 30 species of sharks from the Carcharhinidae and Lamnidae families are known to historically frequent the Balearic Sea in the north-western Mediterranean [9], including some large species with transient semi-pelagic behavior 
such as the great white shark Carcharodon carcharias, which was commonly captured until the late 1970s [10], the copper shark Carcharhinus brachyurus as well as the blacktip shark C. limbatus and the sandbar shark C. plumbeus $[11,12]$. However, the most frequently documented species in these waters is the blue shark Prionace glauca, thanks to its high fecundity [13].

This life history trait provides a certain resilience, particularly with respect to fishing, allowing the classification of this species as "vulnerable" by the IUCN at a global scale [14]. In the 2007 assessment of the species by the IUCN, the Mediterranean populations were listed as "vulnerable" (VU) [3], whereas ten years later they were considered as "critically endangered" (CR) [2]. This new status seems fully justified since a study in the eastern Mediterranean showed that the blue shark enters the swordfish and albacore longline fishery in its first year of life, and the catches consist of both juveniles and adults of both sexes [8]. Today, despite its listing in Appendix III of the Barcelona Convention of 1976 and in Appendix III of the Bern Convention of 1982, the blue shark shows no sign of stock recovery and catch data from the fishing sector remains patchy and incomplete [5].

In this context, fishery independent data for shark species that are particularly vulnerable within the context of pelagic fisheries, are particularly important for decision-makers with an interest in the conservation of sharks [15]. In this study, by using a methodology that does not rely on fishery data, we demonstrate the difficulty of observing the presence of blue sharks in the semipelagic realm of the Balearic Sea. Additionally, the potentially deleterious impact of longline fisheries on the fitness of this species is highlighted, as $50 \%$ of the though small number of animals filmed showed the presence of residual hooks.

\section{Materials and Methods}

For the assessment of shark abundance and the expected low abundance of sharks, we used an innovative prototype of baited remote underwater video system (BRUV) that was able to collect data about shark presence 24-h, including at night [16]. The study was conducted in the Balearic archipelago which is in the western Mediterranean Sea about $200 \mathrm{~km}$ from the east coast of the Iberian Peninsula. The main island of Mallorca is surrounded by four other smaller islands, including the island of Menorca in the northeast (Figure 1A and B). Seawater temperatures in the area most frequently vary between $14-15^{\circ} \mathrm{C}$ in winter and $24-25^{\circ} \mathrm{C}$ in summer.

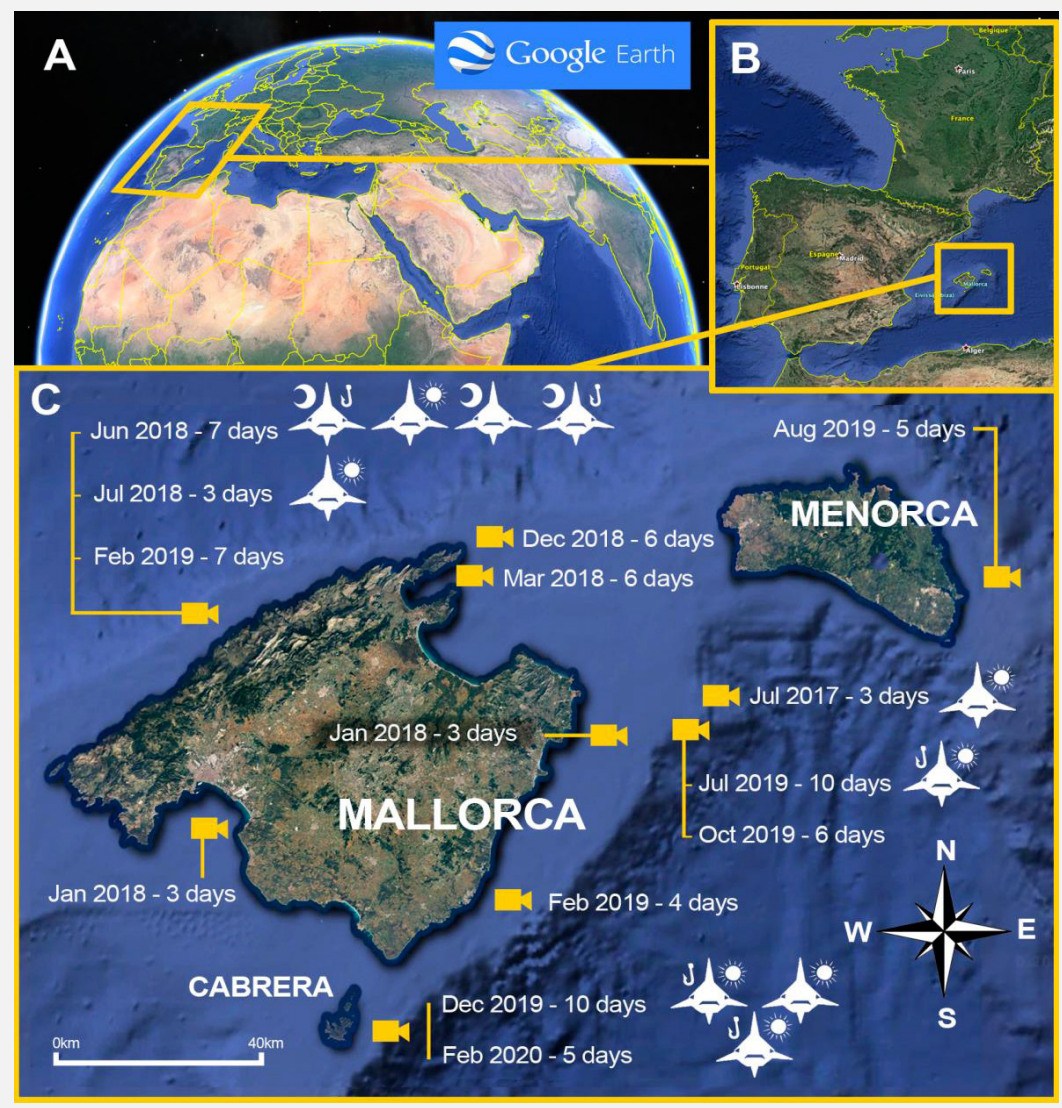

Figure 1: Location of the experiment in the Western Mediterranean basin (A), around two islands in the Balearic archipelago (B), i.e. the main island Mallorca and Menorca (C). C: The location of each session is indicated by a camera with the dates and duration of the session, as well as the number of observed sharks per session. A sun indicates that a shark was observed during the day and a moon indicates that a shark was mostly observed at night. A hook indicates that the shark was holding a residual hook. 
Sampling effort was concentrated around the islands of Mallorca $(n=13)$ and Menorca $(n=1)$, for a total of 14 BRUV deployments which took place between July 2017 and February 2020 , during both winter $(n=8)$ and summer $(n=6)$ (Figure 1). Each deployment -composed of several sessions of $24 \mathrm{~h}$ - lasted from three to 10 days (determined by weather conditions) with an average duration of 120 hours $( \pm 28 \mathrm{~h}$ ) (ESM1). Baits used to attract sharks included fish scraps, cephalopods, and/or cetacean flesh and oil. The continuous video system consisted of a Hero3 GoPro camera (including a $256 \mathrm{~Gb}$ SD memory card that can store up to $27 \mathrm{~h}$ of continuous HD images) in a waterproof housing and an underwater white light source that switched on only at night.

This long-endurance BRUV was kept in place through a nylon line attached to an anchor on the bottom in epi-pelagic waters at an average distance from the coast of $3.8 \mathrm{~km} \mathrm{(+/-3.6} \mathrm{km)} \mathrm{and} \mathrm{an}$ average depth of $75 \mathrm{~m}( \pm 7 \mathrm{~m})$ most of the time near the edge of the continental shelf (Figure 1C, ESM1) with the bait positioned just below the surface. Most of the bait was placed in a closed drum that allowed a continuous dispersal of the olfactive stimuli; in parallel, some fish heads and/or pieces of cetacean flesh hung from nylon (without a hook) in front of the camera to make sure that animals would be properly recorded when approaching the BRUV. Bait and video cards were replaced every $24 \mathrm{~h}$ that constituted a session.

In order to discuss our shark abundance data with those collected in other parts of the world, we calculated the Time of First Arrive (TFA) [17] and we normalized our results by calculating MaxN which is the maximum number of shark individuals of the same species appearing in a frame at the same time [18]; we also calculated the residence time of MaxN (time spent around the BRUV between the first and last appearance on the video) [19]. MaxN per hour was also used to standardize sampling effort across all deployments due to variable soak times, as well as the time of MaxN.

To test the potential effects of environmental variables on the shark occurrence variability we collected the following data through adapted devices: sea surface temperature $\left({ }^{\circ} \mathrm{C}\right)$, current strength (KTS), current direction $\left({ }^{\circ}\right)$, bait quantity and type, and time slot (the $24 \mathrm{~h}$ day being split in four slots of each 6 hours, starting at midnight). Analysis of the data collected has been processed through a Generalized Additive Model (GAM) using $\mathrm{R}$ software. Statistical significance was tested at the p-value $<0.05$ level. Explanatory variables were tested to examine the possible correlation between data (see ESM1 for details).

\section{Results and Discussion}

A total of 1,685 hours of video were accumulated during the 14 continuous observation deployments, distributed between $54.6 \%$ and $45.4 \%$ of the images distributed between day and night, respectively. In total, 10 individual blue sharks were recorded, spending $3.0 \pm 4.41 \mathrm{~h}$ (mean $\pm \mathrm{sd}$; $\min =0,07 \mathrm{~h}$; $\max =$ $11 \mathrm{~h}$ ) around the research set up (Figure 1 and Table 1). The two shortest stays occurred during the day, while the two longest stays occurred at night (Table 1). These results are consistent with the diel behavior of blue sharks, with higher activity in the shallower waters at night [20]. Only distinct individuals were observed, based on photoidentification of the skin marks and dorsal fins.

Table 1: Description and criteria for discrimination of individual sharks with the parameters of their occurrences around the BRUV. \#=Shark ID; $\mathrm{G}=\mathrm{Gender} ; \mathrm{L}=\mathrm{Length}$ of the body; $\mathrm{H} / \mathrm{S}=$ Hook/side of the mouth; N/L=Presence of nylon/Length of the nylon; Bob=Bite on Bait; $T^{\circ}=$ Temperature in ${ }^{\circ} \mathrm{C}$; ToA=Time of Arrival; ToD=Time of Departure; T=Time of residence (between first and last sight on video); TFA=Time For Arrive; MaxN. $\mathrm{h}^{-1}=\mathrm{Max}-$ imum of individuals per hour (calculation based on the entire session).

\begin{tabular}{|c|c|c|c|c|c|c|c|c|c|c|c|}
\hline$\#$ & G & $\mathbf{L}$ & $\mathrm{H} / \mathrm{S}$ & N/L & Вов & $\mathbf{T}^{\circ}$ & ToA & TFA(mn) & $\begin{array}{c}T \\
(\mathrm{mn})\end{array}$ & $\operatorname{MaxN} / \mathrm{h}$ & Specific marking \\
\hline$\# 1$ & $\mathrm{~F}$ & $2-\mathrm{m}$ & No & No/0 & Yes & $25^{\circ} \mathrm{C}$ & $3 \mathrm{PM}$ & 4:00PM & 60 & 0,01818 & $\begin{array}{l}\text { No residual hook. No specific } \\
\text { marking }\end{array}$ \\
\hline$\# 2$ & M & $2-\mathrm{m}$ & Yes/R & Yes $/ 5 \mathrm{~m}$ & Yes & $22^{\circ} \mathrm{C}$ & $10 \mathrm{PM}$ & 9:00AM & 660 & 0,08661 & $\begin{array}{l}\text { Residual hook (right side) } \\
\text { with a nylon leader the } \\
\text { exceeded the shark length } \\
\text { by }<2 \mathrm{~m}\end{array}$ \\
\hline \#3 & M & $1.2-\mathrm{m}$ & No & No/0 & Yes & $22^{\circ} \mathrm{C}$ & $5: 30 \mathrm{PM}$ & $5: 46 \mathrm{PM}$ & 16 & 0,002099 & $\begin{array}{l}\text { No residual hook (compared } \\
\text { to S\#5) }\end{array}$ \\
\hline$\# 4$ & M & $2-\mathrm{m}$ & No & No/0 & No & $22^{\circ} \mathrm{C}$ & $1: 15 \mathrm{PM}$ & $1: 45 \mathrm{PM}$ & 30 & 0,00394 & No hook compared to S\#2 \\
\hline$\# 5$ & M & $1.2 \mathrm{~m}$ & Yes/R & Yes $/ 5 \mathrm{~m}$ & No & $22^{\circ} \mathrm{C}$ & 9:30AM & 11:57AM & 147 & 0,01929 & $\begin{array}{l}\text { Residual hook (right side) } \\
\text { with a nylon leader the } \\
\text { exceeded the shark length } \\
\text { by }>2 \mathrm{~m}\end{array}$ \\
\hline \#6 & $\mathrm{F}$ & $1.6-\mathrm{m}$ & No & No/0 & No & $14^{\circ} \mathrm{C}$ & $12: 54 \mathrm{PM}$ & $13: 22 \mathrm{PM}$ & 28 & 0,00338 & $\begin{array}{l}\text { Different gender from other } \\
\text { animals of similar size (S\#5 } \\
\text { and S\#9) }\end{array}$ \\
\hline \#7 & $\mathrm{F}$ & $2-\mathrm{m}$ & Yes/R & No/0 & No & $26^{\circ} \mathrm{C}$ & $4: 32 \mathrm{AM}$ & 9:09AM & 271 & 0,0193 & $\begin{array}{l}\text { Residual hook (right side) } \\
\text { with heavy algal fooling and } \\
\text { without nylon leader }\end{array}$ \\
\hline
\end{tabular}




\section{Oceanography \& Fisheries Open access Journal}

\begin{tabular}{|c|c|c|c|c|c|c|c|c|c|c|c|}
\hline \#8 & M & $2.5-\mathrm{m}$ & Yes/L & Yes/4m & No & $16^{\circ} \mathrm{C}$ & $2: 56 \mathrm{PM}$ & $2: 55 \mathrm{AM}$ & 719 & $0,03745 \quad \begin{array}{c}\text { Residual hook (right side) } \\
\text { with a nylon leader that } \\
\text { exceeded the shark length } \\
\text { by }>2 \mathrm{~m}\end{array}$ \\
\hline \#9 & $\mathrm{M}$ & $1.6-\mathrm{m}$ & No & No/0 & No & $16^{\circ} \mathrm{C}$ & $12: 25 \mathrm{PM}$ & $13: 48 \mathrm{PM}$ & 83 & 0,00432 & single male of the size \\
\hline \#10 & F & $1.8-\mathrm{m}$ & Yes/R & Yes/7m & No & $15^{\circ} \mathrm{C}$ & $6: 21 \mathrm{PM}$ & $6: 25 \mathrm{PM}$ & 4 & $0,00046 \quad \begin{array}{c}\text { Residual hook (right side) } \\
\text { with a nylon leader and a } \\
\text { piece of net that exceeded } \\
\text { the shark length }\end{array}$ \\
\hline
\end{tabular}

Additionally, the 10 sharks could be discriminated based on their gender determined by the presence or absence of external claspers behind their pelvic fins, i.e. a slight unbalanced sex-ratio with more males $(n=6)$ than females $(n=4)$, their respective sizes between 1.2 and $2.5 \mathrm{~m}$ in total length (TL) assessed by their passage close to the bait drum that may have served as a metric reference and the presence $(n=5)$ or absence $(n=5)$ of residual hooks on the side of the mouth (Figure 1 and Table 1). The sizes of observed animals are consistent with previous studies showing that the total length (LT) among the catches of a total of 870 blue sharks was ranging from 70 to $349 \mathrm{~cm}$, sampled from the swordfish longline fishery in the Mediterranean Sea during the period 1998-2003 [21].

The majority of our sharks $(70 \%, n=7)$ were observed in summer, compared to $30 \%(\mathrm{n}=3)$ in winter, which is coherent with findings that blue sharks were more frequently encountered during late summer in cool water masses during fishing trials in the Eastern Mediterranean sea [22]. Regarding the external variables that were tested for their contribution to shark occurrence, the final GAM explained $22,7 \%$ of the variability and only retained the current direction as a predictor (see ESM 1 for details). Nevertheless, the current direction was not a significant variable leading to the presence/absence of animals in the studied sites ( $\mathrm{p}$-value $=0.067$ ). Such a result can be explained by the very low number of occurrences of sharks compared to the extensive sampling effort.

In that respect, the best MaxN recorded was 1, as each observed single shark showed up alone in front of the camera, and the average MaxN.h-1 (taking into consideration the sampling effort) for shark abundance was $0,020 \pm 0,025$ (Table 1) which is definitely among the lowest figures that were recorded around the world through similar methodologies involving BRUVs. Indeed, we could not expect from a temperate pelagic species figures equivalent to those of coastal tropical areas, which are known to hold high densities of sharks with MaxN.h-1 reaching an average of 4 and 2 (i.e. 100 to 200 times higher) for two kinds of areas benefiting or not, respectively, from a protection from fishing in the Australian Great barrier reef [23].

However, the comparison with video sessions baited in pelagic midwater (over $60 \mathrm{~m}$ depths) in Australia, shows that the two local pelagic Carcharhinidae species, the blacktip shark (Carcharhinus limbatus) and sandbar shark (C. plumbeus) respectively, reached their MaxN with an average TFA of less than 90 min [19], also shows an important difference (with a coefficient of the order of 40) with the average TFA for the 10 blue shark that was approximately $62 \mathrm{~h}$; the minimum TFA being of $13 \mathrm{~h}$ in the Soller session that displayed the higher abundance of sharks $(n=4)$ (Table 1$)$. The use of BRUVS to reliably assess the abundance of shark's species was validated in other regions of the world $[24,25]$, as well as the pelagic zone. They also have proven to be an effective technology for counting sharks at low densities, including identifying species considered locally extinct as was the case in oceanic islands in Brazil [26].

In this context, our methodology was appropriate to evaluate the presence rate of the blue shark around the Balearic Islands despite its limited abundance. We can also consider that our innovative technology which allowed for the accumulation of video images over a period of 24 hours a day [16] was an additional asset with regards to the objective of observing potentially low-density animals. In this context, the use of BRUVS helps to demonstrate that sharks in general, and to a lesser degree the blue shark, are in extremely low abundance in this part of the Mediterranean $[1,5]$. Beyond the issue of shark abundance, the most interesting discovery of our study lies in the very high proportion (50\%) of animals which show residual hooks, very likely due to after-effects of interactions with pelagic fisheries (Figure 1 and Table 1).

This proportion is higher than that recently observed in the context of an artificial provisioning site in French Polynesia where $38 \%$ of the observed tiger sharks Galeocerdo cuvier $(\mathrm{n}=55)$ held between one and six residual hooks [27]. In the framework of this study, the authors concluded that for fisheries management modelling purposes, it may be possible to directly extrapolate hook retention/shedding rate observations from Tahitian tiger sharks to other large warm water shark species that are frequently captured in longline fisheries but difficult to observe in their natural habitats (e.g. oceanic whitetip shark, C. longimanus). Although it deals with another pelagic shark species, our study suggest that the impact of pelagic longline fisheries may be greater in the context of the Mediterranean.

Regarding the tiger shark which is one of the most robust shark species in fisheries interactions with $<10 \%$ at-vessel mortality and $>97 \%$ post-release survival in long-line fisheries [28], Bègue et al. [27] suggested that the hooks do not jeopardize the short-term survival of the animals. Nevertheless, the impact of residual hooks on animal survival is probably of greater concern for the blue shark, which is significantly smaller (average of 1.8 
$\mathrm{m}$ TL in our study) than the tiger shark (often $>3 \mathrm{~m}$ TL). As such, and at the simple scale of our sampling, we were able to observe a difference in the ingestion efficiency of the bait (without hooks) offered to the sharks in order to keep them in the camera field (see Material and Method section).

Shark \#2 (a 2-m male with a residual hook- (Figure 2A) spent more time ( $\mathrm{t}=48 \mathrm{~s})$ trying, but not managing, to ingest the suspended bait (ESM 2) than did shark \#3, which was a smaller individual (1.2 m TL) without a residual hook (Table 1), that managed to take a similar bait in less than 23s (ESM 3). Therefore, it is possible that the presence of hooks may interfere with the survival of animals that might die because of these interactions with longlines, although this is difficult to quantify [29,30]. In quantitative terms, the presence of these hooks can only reduce the high post-harvest survival rates calculated for this species (following the release of animals in good physical condition and without a hook) to be around $85 \%$ [31]. In addition, we must consider that post-harvest survival rates for this species are positively correlated with size [32].
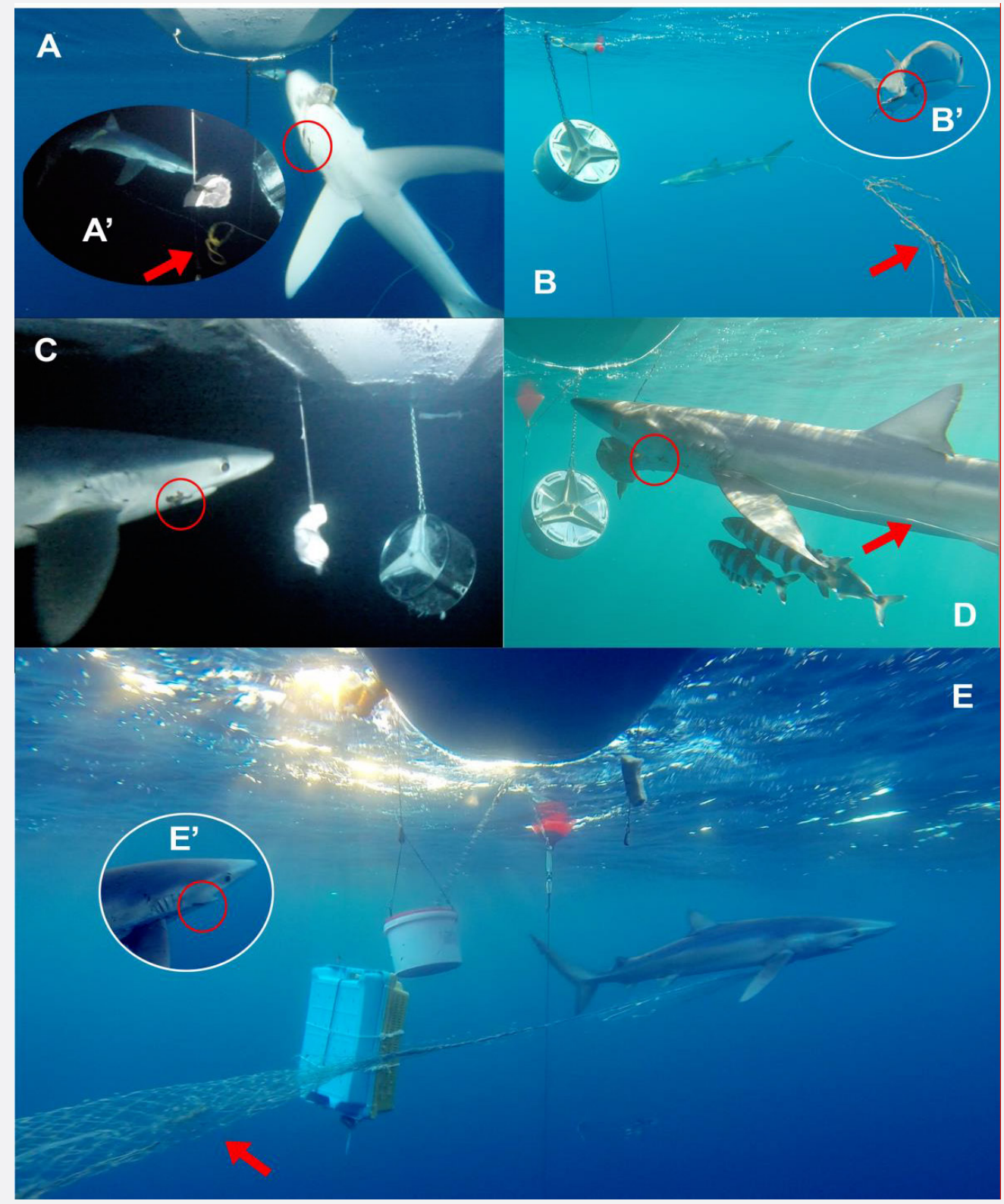

Figure 2: A, B, C, D and E: images extracted from underwater videos showing the presence of hooks (in the red circles) on five of the ten sharks filmed near the BRUV. These residual hooks potentially interfere with optimal food ingestion capabilities, as seen visually with the individual in A (see ESM2). Four (all except for C) of the five animals dragged nylon line (indicated by the red arrows) from the longlines on which they were caught. E: In addition to the nylon (leader upstream of the hook) a shark also dragged a piece of net, constituting an important inertia and a consequent inconvenience for swimming. 
Therefore, the combined effects of the low average size of the sharks observed within the framework of our study (average of 1.8 TL that is half of the maximum length for the species around $3.5 \mathrm{~m}$ ) and the presence of residual hooks should require more attention as they might be contributing factors to a high cryptic mortality of blue sharks in relation to pelagic fisheries in this part of the Mediterranean. Observations made in this study led us to conclude that West-Mediterranean blue shark populations present a low abundance and are likely subject to unsustainable fishing pressure [5], potentially reducing their fitness, which clearly jeopardizes the local future of a critically endangered species.

Supplementary Materials: The ESM1, ESM2 and ESM3 files are available through the website: www.sharkmed.org

Acknowledgement: The authors wish to thank Pr Guillem Mateu Vicens (UIB) for his advice and support in developing this common project, Dr Carl Meyer from the University of Hawaii for some editing suggestions as well as the Palma Aquarium for providing us with bait and the Conselleria Medi Ambient, Agricultura i Pesca of Mallorca (Spain) for providing us authorization for our studies. Funding: The Shark Med project gets the financial support of the Marilles Foundation (www. marilles.org).

Funding: The Shark Med project gets the financial support of the Marilles Foundation (www.marilles.org).

\section{References}

1. Ferretti F, Myers RA, Serena F, Lotze HK (2008) Loss of large predatory sharks from the Mediterranean Sea. Conservation Biology 22(4): 952964.

2. Dulvy N, Allen D, Ralph G, Walls R (2016) The Conservation Status of Sharks, Rays and Chimaeras in the Mediterranean Sea (Brochure). IUCN, Malaga, Spain.

3. Cavanagh RD, Gibson C (2007) Overview of the Conservation Status of Cartilaginous Fishes (Chondrichthyans) in the Mediterranean Sea. IUCN, Gland, Switzerland and Malaga, Spain, Pp.42.

4. Megalofonou P (2005) Incidental catch and estimated discards of pelagic sharks from the swordfish and tuna fisheries in the Mediterranean Sea. Fishery Bulletin 103(4): 620-634.

5. Biton-Porsmoguer S, LLoret J (2018) Potentially unsustainable fisheries of a critically endangered pelagic shark species: the case of the blue shark (Prionace glauca) in the Western Mediterranean Sea. Cybium 42(3): 299-302.

6. Burgess E, Dimech M, Caruana R, Darmanin M, Raine H, et al. (2010) Non-target by-catch in the Maltese bluefin tuna (Thunnus thynnus) longline fishery (Central Mediterranean).

7. Megalofonou P, Damalas D, Yannopoulos C (2005) Composition and abundance of pelagic shark by-catch in the eastern Mediterranean Sea. Cybium 29(2): 135-140.

8. Megalofonou P, Damalas D, Deflorio M, De Metrio G (2009) Modeling environmental, spatial, temporal, and operational effects on blue shark by-catches in the Mediterranean long-line fishery. Journal of Applied Ichthyology 25: 47-55.
9. Serena F (2005) Field identification guide to the sharks and rays of the Mediterranean and Black Sea. Food and Agriculture Organization of the United Nations.

10. Morey G, Martinez M, Massuti E, Moranta J (2003) The occurrence of white sharks, Carcharodon carcharias, around the Balearic Islands (western Mediterranean Sea). Environmental Biology Fishes 68: 425432

11. Morey G, Massuti E (2003) Record of the copper shark, Carcharhinus brachyurus, from the Balearic Islands (Western Mediterranean). Cybium 27(1): 53-56.

12. Morey G, Soldo A, Riera F, Serena F (2008) Records of Carcharhinus limbatus and C. plumbeus (Chondrichthyes: Carcharhinidae) from off the Balearic Islands (NW Mediterranean). Cybium 32(3): 195-200.

13. Cortés E, Arocha F, Beerkircher L, Carvalho F, Domingo A, et al. (2010) Ecological risk assessment of pelagic sharks caught in Atlantic pelagic longline fisheries. Aquatic Living Resources 23(1): 25-34.

14. Camhi MD, Valenti SV, Fordham SV, Fowler SL, Gibson C (2009) The conservation status of pelagic sharks and rays. In: IUCN Species Survival Commission Shark Specialist Group, University of Oxford, UK, P. 78.

15. Queiroz N, Humphries NE, Couto A, Vedor M, Da Costa I, et al. (2019) Global spatial risk assessment of sharks under the footprint of fisheries. Nature 572(7770): 461-466.

16. Torres A, Abril AM, Clua EE (2020) A Time-Extended (24 h) Baited Remote Underwater Video (BRUV) for Monitoring Pelagic and Nocturnal Marine Species. Journal of Marine Science and Engineering 8(3): 208.

17. Priede IG, Merrett NR (1996) Estimation of abundance of abyssal demersal fishes; a comparison of data from trawls and baited cameras. Journal of Fish Biology 49: 207-216.

18. Willis TJ, Millar RB, Babcock RC (2000) Detection of spatial variability in relative density of fishes: Comparison of visual census, angling, and baited underwater video. Mar Ecol Prog Ser 198: 249-260.

19. Letessier T B, Meeuwig JJ, Gollock M, Groves L, Bouchet PJ, et al. (2013) Assessing pelagic fish populations: The application of demersal video techniques to the mid-water environment. Methods in Oceanography 8: 41-55.

20. Stevens JD, Bradford RW, West GJ (2010) Satellite tagging of blue sharks (Prionace glauca) and other pelagic sharks off eastern Australia: depth behavior, temperature experience and movements. Marine biology 157(3): 575-591.

21. Megalofonou P, Damalas D, De Metrio G (2009) Biological characteristics of blue shark, Prionace glauca, in the Mediterranean Sea. Marine Biological Association of the United Kingdom. Journal of the Marine Biological Association of the United Kingdom 89.

22. Damalas D, Megalofonou P (2010) Environmental effects on blue shark (Prionace glauca) and oilfish (Ruvettus pretiosus) distribution based on fishery-dependent data from the eastern Mediterranean Sea. Journal of the Marine Biological Association of the United Kingdom. 90(3): 467-480.

23. Espinoza M, Cappo M, Heupel MR, Tobin AJ, Simpfendorfer CA (2014) Quantifying Shark Distribution Patterns and Species-Habitat Associations: Implications of Marine Park Zoning. PLoS ONE 9(9): e106885.

24. Santana-Garcon J, Braccini M, Langlois TJ, Newman SJ, McAuley RB, et al. (2014) Calibration of pelagic stereo-BRUV s and scientific longline surveys for sampling sharks. Methods in Ecology and Evolution 5(8): 824-833. 
25. Rizzari JR, Frisch AJ, Connolly SR (2014) How robust are estimates of coral reef shark depletion? Biological Conservation 176: 39-47.

26. Pimentel CR, Andrades R, Ferreira CE, Gadig OB, Harvey ES, et al. (2020) BRUVS reveal locally extinct shark and the way for shark monitoring in Brazilian oceanic islands. Journal of Fish Biology 96(2): 539-542.

27. Bègue M, Clua E, Siu G, Meyer C (2020) Prevalence, persistence and impacts of residual fishing hooks on tiger sharks. Fisheries Research 224: 105462 .

28. Ellis JR, McCully Phillips SR, Poisson F (2017) A review of capture and post-release mortality of elasmobranchs. Journal of Fish Biology 90: 653-722.

29. Gilman E, Clarke S, Brothers NJA-S, Mandelmann J, Mangel J, et al.
(2007) Shark Depredation and Unwanted Bycatch, Western Pacific Regional Fishery Management. Council Honolulu, USA.

30. Molina JM, Cooke SJ (2012) Trends in shark bycatch research: status and research needs. Reviews in Fish Biology and Fisheries 22(3): 719737.

31. Musyl MK, Brill RW, Curran DS, Fragoso NM, McNaughton LM, et al. (2011) Post release survival, vertical and horizontal movements, and thermal habitats of five species of pelagic sharks in the central Pacific Ocean. Fishery Bulletin 109(4): 341-368.

32. Diaz GA, Serafy JE (2005) Longline-caught blue shark (Prionace glauca): factors affecting the numbers available for live release. Fishery Bulletin 103(4): 720 .

Your next submission with Juniper Publishers will reach you the below assets

- Quality Editorial service

- Swift Peer Review

- Reprints availability

- E-prints Service

- Manuscript Podcast for convenient understanding

- Global attainment for your research

- Manuscript accessibility in different formats ( Pdf, E-pub, Full Text, Audio)

- Unceasing customer service

Track the below URL for one-step submission https://juniperpublishers.com/online-submission.php 